\title{
Diversité agroécosystémique et devenir des céréales traditionnelles au sud du Mali
}

Mamy Soumaré ${ }^{1}$

Didier Bazile ${ }^{2}$

Michel Vaksmann ${ }^{3}$

Mamoutou Kouressy ${ }^{1}$

Kadiatou Diallo ${ }^{1}$

Cheick Hamala Diakité ${ }^{1}$

${ }^{1}$ Institut d'économie rurale (IER),

Sotuba,

BP 438,

Bamako

Mali

<mamy.soumare@ier.ml>

<mamoutou.kouressy@ier.ml>

$<$ Kadiatou.diallo@ier.ml>

$<$ hamala.diakite@ier.ml>

${ }^{2}$ Centre de coopération internationale en recherche agronomique

pour le développement (Cirad),

Département Environnements \& Sociétés,

UPR 47 " GREEN »,

Campus international de Baillarguet

TA C-47/F.

34398 Montpellier cedex 5

<didier.bazile@cirad.fr>

${ }^{3}$ Centre de coopération internationale

en recherche agronomique

pour le développement (Cirad),

BP 1813,

Bamako

Mali

<michel.vaksmann@cirad.fr>

\begin{abstract}
Résumé
À partir d'un dispositif de recherche à échelles emboîtées, de l'exploitation agricole à la région, cette étude analyse la diversité des agroécosystèmes, la place des céréales traditionnelles (mil, sorgho) dans les assolements et l'évolution des systèmes de culture et des pratiques dans les exploitations. En fonction des échelles d'observation, la place des différentes cultures varie. À l'échelle régionale, le sorgho reste une culture importante à travers l'extension de son aire de culture et la surface cultivée par actif. Au niveau des exploitations, l'évolution des systèmes de culture est marquée par leur diversification. La place du sorgho diminue et cette régression ne s'explique plus uniquement par le développement du maïs car le mil aussi se développe. Le mil contribue maintenant davantage à la formation des revenus des exploitations et sa culture commence à s'intensifier par le recours aux engrais. La diminution de la taille des soles de sorgho et l'augmentation continue du mil peuvent contribuer, selon les choix des agriculteurs, au maintien ou à la diminution de la diversité variétale.
\end{abstract}

Mots clés : agrobiodiversité ; Mali ; mil ; sorgho ; système de culture.

Thèmes : productions végétales ; ressources naturelles et environnement.

\section{Abstract}

Agroecosystemic diversity and future of traditional cereals in the Malian cotton belt

Biodiversity can be analyzed at multiple scales: gene, variety, population, species and ecosystem. There are strong interactions between diversity with each of these levels. By scaling up from farm to regional scale, this study analyzes the diversities of agroecosystems, the evolution of cultivated species and cropping systems. According to the scale of analysis, the place of different crops changes. At the regional level sorghum is an important crop. But on farms, the cropping system evolution is characterized by diversity and the increasing place of millet in the regions which traditionally cultivated mainly sorghum and maize. Maize development is not the unique reason of sorghum depletion as the increase of millet also contributes to securing farmers income. Whether the decline of sorghum and the progress of millet will affect cultivar diversity positively or not will depend on the choices made by the farmers.

Key words: agrobiodiversity; cropping systems; Mali; millets; sorghum grain.

Subjects: natural resources and environment; vegetal productions.

a diversité biologique est classiquement appréhendée aux différentes échelles de la structuration du vivant : gène, variété, population, écosystème. Mais la particularité de l'agrobiodiversité nécessite une nouvelle dimension d'étude, celle de la diversité des pratiques humaines. L'activité agricole a longtemps été considérée comme un facteur contribuant fortement à la diminution de la biodiversité. Mais les pratiques de sélection des plantes depuis

Tirés à part : M. Soumaré 
l'origine de l'agriculture font que l'homme peut aussi être un facteur de maintien et d'amélioration de la diversité biologique pour valoriser et diversifier l'existant afin de l'adapter à une mise en valeur des milieux et des territoires en évolution (Wood et Lenné, 1999).

Dans les zones cotonnières au sud du Mali, suite au développement de la culture du maîs et du coton à partir des années 1980, les paysans ont accordé une moindre importance à la culture du mil [Pennisetum Glaucum (L.) R. Br] et du sorgho [Sorghum Bicolor (L.) Moench] (Bazile et Soumaré, 2004). Face à cette évolution, il paraissait important d'explorer au sein de la diversité des agroécosytèmes cotonniers actuels l'évolution de la place des céréales traditionnelles, mil et sorgho. Pour cela nous faisons l'hypothèse que dans les mêmes conditions écologiques et, face à des politiques agricoles similaires, les agriculteurs peuvent mettre en place des systèmes de culture (SC) différents. Nous discutons ensuite, sur la base des études existantes au Mali, comment cette diversité des pratiques agricoles peut contribuer à la diversification des cultures et au maintien ou à la régression de la diversité variétale des espèces cultivées.

\section{Méthodologie}

Ce travail s'appuie sur deux facteurs : la diversité des systèmes de production (SP) et des SC à l'échelle régionale et l'évolution des pratiques agricoles au niveau des exploitations.

\section{Diversité \\ à l'échelle régionale}

Nous utilisons la caractérisation des systèmes agraires localisés (SAL) établis par Soumaré et al. (2006) dans les zones cotonnières au Mali. Ils ont été définis par une méthode de zonage territorial ascendant depuis l'analyse des déterminants des SP jusqu'à la diversité de leurs combinaisons au sein des communes rurales qui composent les SAL définis à l'échelle régionale. L'analyse couvre l'ensemble de l'aire géographique du sud du Mali pour une pluviométrie comprise entre 600 et $1400 \mathrm{~mm}$. La mise en forme d'informations homogènes issues d'enquêtes réalisées entre 1999 et 2003 sur 6290 exploitations réparties sur 125 villages a permis de construire une base de données structurée autour de 50 variables caractérisant la structure des exploitations (population, équipement, élevage et cultures). Une analyse en composantes principales (ACP) a été réalisée sur les 31 variables les plus discriminantes. L'ACP a permis d'identifier 9 SP principaux. Le poids de chacun d'eux est traduit en pourcentage à l'échelle communale ${ }^{1}$ afin d'effectuer une analyse factorielle des correspondances (AFC). Dix combinaisons de SP ont ainsi été mises en évidence à l'échelle de la commune rurale. La distribution spatiale de ces combinaisons a été superposée dans un système d'information géographique (SIG) avec deux facteurs englobants - la pluviométrie et les densités de peuplement -, puis confrontée aux zonages existants sur la zone pour préciser les contours des SAL. La validation des 15 SAL issus de l'analyse de données a été réalisée en procédant à des transects paysagers traversant chaque SAL.

Des enquêtes complémentaires sur certains villages ont permis de regrouper les 15 SAL en 7 zones agricoles (figure 1) en fonction de l'importance des cultures intensives utilisant des intrants (coton et maïs) et traditionnelles (mil et sorgho). Quelques indicateurs sur les surfaces cultivées dans les exploitations ont été agrégés au niveau village et spatialisés par interpolation à l'échelle des 7 zones pour appréhender les SC à cette échelle. Nous considérons la surface par actif comme indicateur pertinent car la main-d'œuvre demeure la principale contrainte pour les SP dans ces régions (Tersiguel 1995; Milleville et Serpantier 2007).

\section{Diversité au sein des exploitations}

L'analyse régionale (zonage ascendant et interpolation) ne rend pas compte de l'évolution des pratiques au sein des exploitations. Pour aborder cette question, des enquêtes approfondies ont été conduites au sein de 15 exploitations dans 3 villages représentatifs des systèmes agraires dominants au sud du Mali : Dentiola dans le système à ager/saltus en crise, Bohi dans le système à ager/saltus en équilibre, et Diou dans le système à abatis/brûlis (figure 1). L'ager est un espace cultivé de façon continue. Le saltus correspond à des espaces non cultivés servant de pâturages et produisant du

\footnotetext{
${ }^{1}$ Une commune rurale au Mali regroupe de 5 à 10 villages.
}

bois. C'est le bétail qui assure le transfert des matières organiques et minérales du saltus vers l'ager pour permettre la reproduction de la fertilité du sol (Dufumier, 2005).

Le choix de l'échantillon repose sur des éléments de structure (population, équipement, surfaces cultivées), de diversification des pratiques (élevage, culture de contre-saison, culture de bas-fonds, arboriculture) et sur l'origine des exploitations (autochtones ou migrants). Les enquêtes ont permis de tracer l'évolution de certaines pratiques (assolement, fertilisation, production) sur les 25 dernières années.

\section{Résultats}

\section{Les systèmes de production et de culture à l'échelle régionale}

Les SP et les SC sont définis à l'échelle de l'exploitation. Mais le SC peut aussi être appréhendé à différentes échelles, et Jouve (2003) montre que l'analyse de la répartition des cultures, dans l'espace et le temps, à des échelles inférieures (région, pays, etc.) ouvre de nouvelles perspectives pour la compréhension des pratiques agricoles. D'une zone agricole à l'autre, les combinaisons de SC et de SP varient.

\section{La zone nord soudano-sahélienne}

Cette partie septentrionale est caractérisée par une majorité d'exploitations peu ou moyennement équipées avec de faibles effectifs de bovins. Le coton est rarement cultivé mais, au centre de cette zone, on note la présence de quelques exploitations cotonnières, environ $15 \%$ du total. Les SC sont basés sur les céréales avec une rotation principale $\mathrm{mil} / \mathrm{sorgho}$, avec respectivement 0,5 et $0,30 \mathrm{ha} /$ actif, et accessoirement sur l'arachide (tableau 1 et figure 2).

\section{Le vieux bassin cotonnier}

L'évolution de l'agriculture de cette zone est la plus aboutie, avec une forte intensification s'appuyant sur les intrants, la fumure animale, la culture attelée et une forte mobilisation de la main-d'œuvre. Cette zone se caractérise par de fortes densités de population rurale (jusqu'à 70 hab. $/ \mathrm{km}^{2}$ dans certaines parties), une complémentarité saltus/ager et une disparition quasi totale des jachères. Cette inten- 


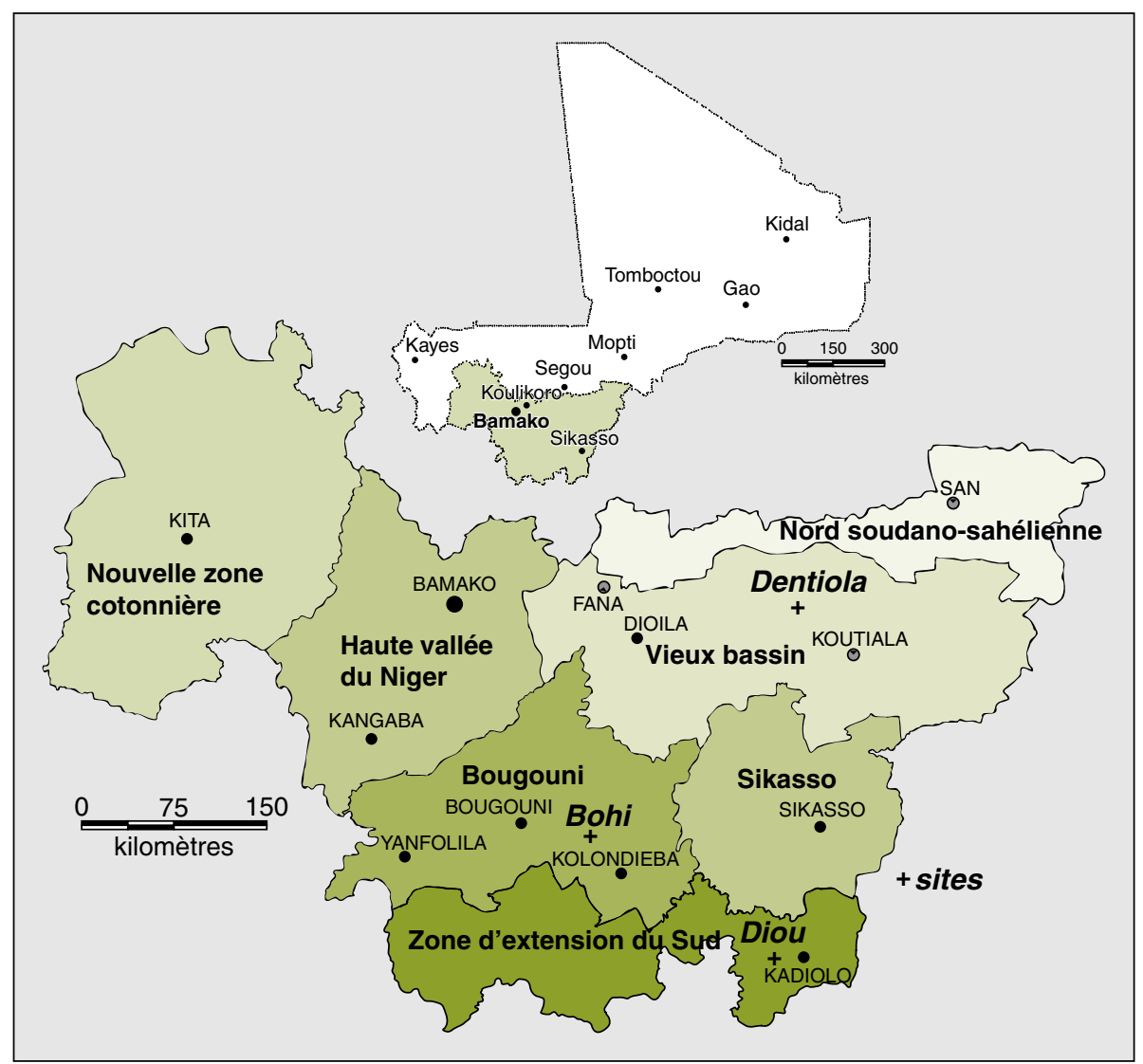

Figure 1. Carte des régions agricoles et de la localisation des sites.

Figure 1. Map of agricultural regions and site locations. sification a recours aux transferts de matière organique entre le saltus et l'ager alors que les disponibilités fourragères sont en train de diminuer du fait d'une dégradation des parcours. Cela complique le maintien des troupeaux bovins toute l'année dans cette zone et donc affecte l'importance de ces transferts de fertilité. Ces agroécosytèmes sont en crise. L'extension des surfaces ne se poursuit plus que dans les marges ou périphéries sud qui correspondent aux zones les moins peu-

\section{Tableau 1. Surface cultivée (hectares) par actif des principales cultures dans les régions agricoles.}

Table 1. Cultivated area (hectares) by working person for the main cultures.

\begin{tabular}{|c|c|c|c|c|c|c|}
\hline \multirow[t]{2}{*}{ Région agricole } & \multicolumn{6}{|c|}{ Surface cultivée par actif } \\
\hline & Arachide & Coton & Maïs & Mil & Sorgho & Total \\
\hline Nord soudano-sahélienne & 0,12 & 0,14 & 0,07 & 0,43 & 0,27 & 1,03 \\
\hline Vieux bassin cotonnier & 0,12 & 0,33 & 0,16 & 0,39 & 0,37 & 1,37 \\
\hline $\begin{array}{l}\text { Zone de diversification } \\
\text { de Sikasso }\end{array}$ & 0,06 & 0,34 & 0,18 & 0,14 & 0,25 & 0,97 \\
\hline $\begin{array}{l}\text { Bassin céréalier } \\
\text { de Bougouni }\end{array}$ & 0,15 & 0,28 & 0,17 & 0,25 & 0,24 & 1,09 \\
\hline Zone d'extension du Sud & 0,12 & 0,27 & 0,23 & 0,16 & 0,21 & 0,99 \\
\hline Haute vallée & 0,21 & 0,14 & 0,12 & 0,25 & 0,25 & 0,97 \\
\hline Nouvelle zone cotonnière & 0,23 & 0,27 & 0,10 & 0,16 & 0,23 & 0,99 \\
\hline
\end{tabular}

plées. Plus de $80 \%$ des exploitations ont un équipement de culture attelée complet avec 1 charrue et 2 boufs. Les SC sont orientés coton/maïs au centre et au sud, et coton/sorgho à l'ouest pour plus de $50 \%$ des exploitations.

\section{La zone de diversification de Sikasso}

À Sikasso, les densités de population sont plus faibles $\left(30 \mathrm{hab} . / \mathrm{km}^{2}\right)$ et les conditions naturelles plus favorables: pluviométrie abondante, parcours riches et étendus, espace cultivable extensible. Les contraintes sur les facteurs de production sont essentiellement liées à la maind'œuvre. Celle-ci fait principalement défaut lors des entretiens culturaux. La surface importante des bas-fonds contribue à l'essor de nombreuses cultures comme les tubercules (pomme de terre, patate douce, etc.) et à la mise en place de vergers conséquents (manguiers, agrumes, etc.). Les SC pluviaux stricts sont basés sur le coton et le maïs. Le coton est la principale culture avec plus d'un tiers d'hectare par actif, sa part pouvant parfois atteindre $50 \%$ de l'assolement dans certaines exploitations.

\section{Le bassin céréalier de Bougouni}

Cette zone se situe à la même latitude que Sikasso, mais plus à l'ouest ; en conséquence, elle bénéficie des mêmes conditions climatiques. Plus du tiers des exploitations consacrent, à côté du coton, une majorité de leurs surfaces cultivées à l'arachide au mil et au sorgho.

On note l'extension de la ceinture de culture du sorgho à cette zone alors que celle du maïs ne touche que partiellement sa partie sud (figure 2). C'est la traduction spatiale de l'importance du sorgho par rapport au maïs en surface cultivée par actif alors que, dans les autres zones cotonnières soumises aux mêmes conditions pluviométriques, c'est le contraire qu'on observe. On peut donc conclure que malgré les conditions favorables à son développement, le maïs ne s'est pas substitué au sorgho dans cette zone.

\section{Les zones d'extension agricole du Sud}

Le système d'abattis-brûlis (ou agriculture itinérante sur brûlis) reste dominant même si les cultures intensifiées - maïs et coton - sont présentes dans les assolements. Le mil et le sorgho occupent une place moins importante par rapport au maïs. L'intensification agricole progresse actuellement avec le développement de la culture du coton. Les exploitations à fortes capacités d'investissement en 


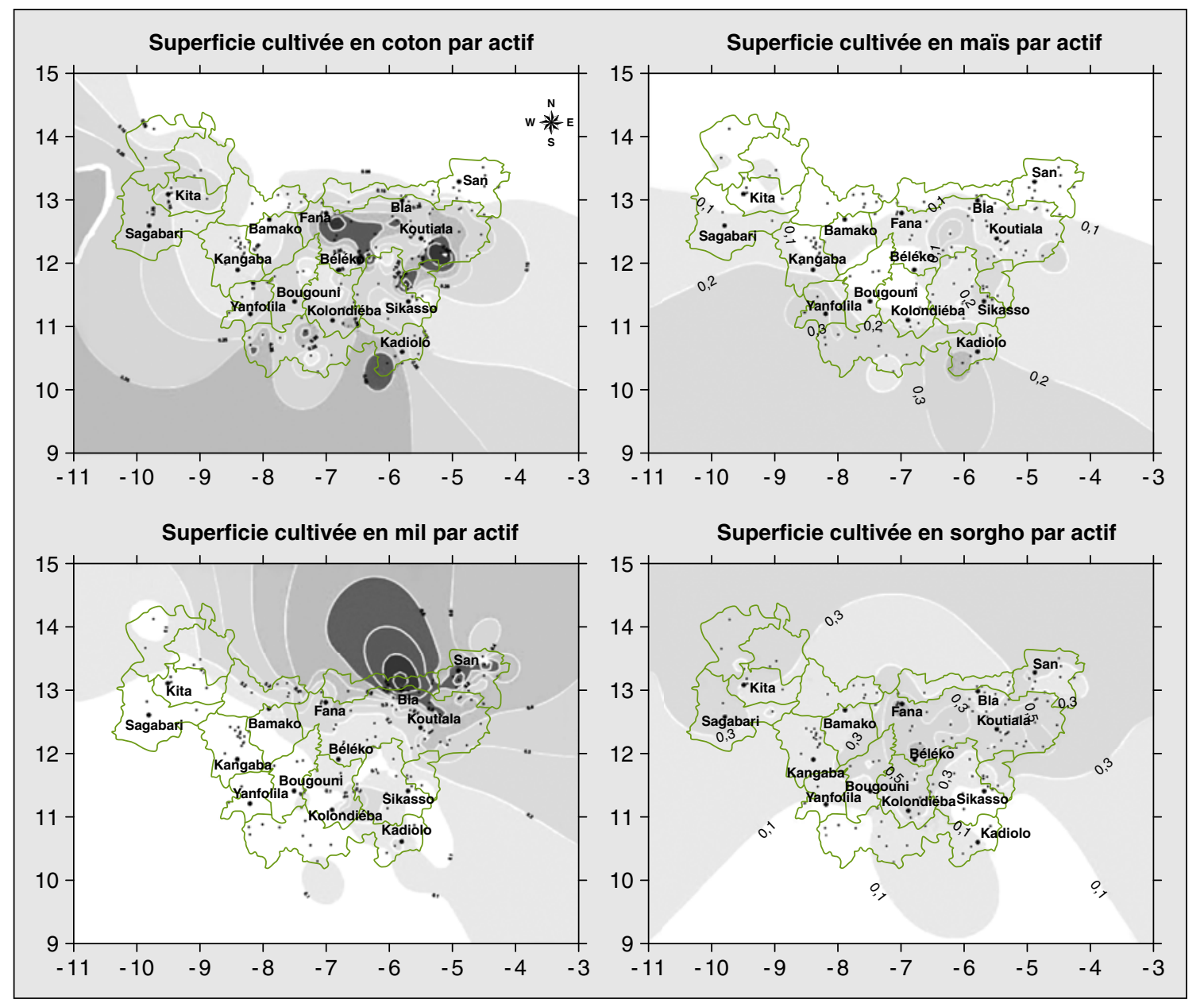

Figure 2. Répartition spatiale des superficies cultivées par actif pour les principales cultures du système coton : coton, maïs, mil et sorgho.

Figure 2. Spatial distribution of cultivated surfaces (ha/agricultural active) obtained by interpolation.

intrants abandonnent progressivement l'abatis-brûlis.

\section{La Haute vallée du Niger}

Cette unité géographique s'étend autour de Bamako. Elle est déjà densément peuplée et soumise à l'urbanisation croissante. Les SC sont orientés sur les céréales, mil et sorgho $(0,25 \mathrm{ha} /$ actif $)$ et l'arachide $(0,21 \mathrm{ha} /$ actif $)$ plutôt que sur coton/maïs $(0,14$ et $0,12 \mathrm{ha} / \mathrm{actif})$. Les limites des champs sont progressivement matérialisées à l'aide de haies, certainement à cause des pressions urbaines sur le foncier rural.

\section{La nouvelle zone cotonnière autour de Kita}

Suite aux problèmes de commercialisation, la culture arachidière a été progressivement abandonnée dans cette zone située à l'extrême-ouest du Mali-Sud. Le coton y est en progression depuis 1995 avec le début des interventions de la société cotonnière (CMDT, Compagnie malienne pour le développement des textiles). Le système agraire ancien reposant sur l'abattis-brûlis domine toujours et les terres arables sont abondantes. Les SC sont principalement basés sur le sorgho, le coton et l'arachide (tableau 1) avec près de $0,3 \mathrm{ha} /$ actif pour chacun. Le mil et le maïs se situent respectivement à 0,10 et 0,17 ha/actif. Les possibilités d'extension des surfaces cultivées sont réelles (à l'exception de la zone périurbaine de Kita) mais les agriculteurs souffrent d'un manque d'équipement et de l'enclavement de leur village.

\section{Évolution des SC à l'échelle des exploitations}

Cette évolution a été construite à partir de l'analyse des pratiques agricoles sur les
25 dernières années chez 15 exploitations dans chacun des trois villages d'étude.

\section{Augmentation des surfaces cultivées}

En 25 ans, les surfaces cultivées ont doublé. Cette extension connaît maintenant une certaine stabilité à Dentiola et Bohi, où, après de grandes phases d'extension, les surfaces augmentent désormais moins vite. À Diou, où l'agriculture est restée longtemps manuelle, on note aujourd'hui le plus fort taux d'accroissement des surfaces (>160\% entre 1980 et 2005). Cela s'explique par la dynamique d'équipement en culture attelée couplée à l'utilisation intensive des intrants (figure 3) permettant d'accroître la durée de culture, voire la culture continue. 


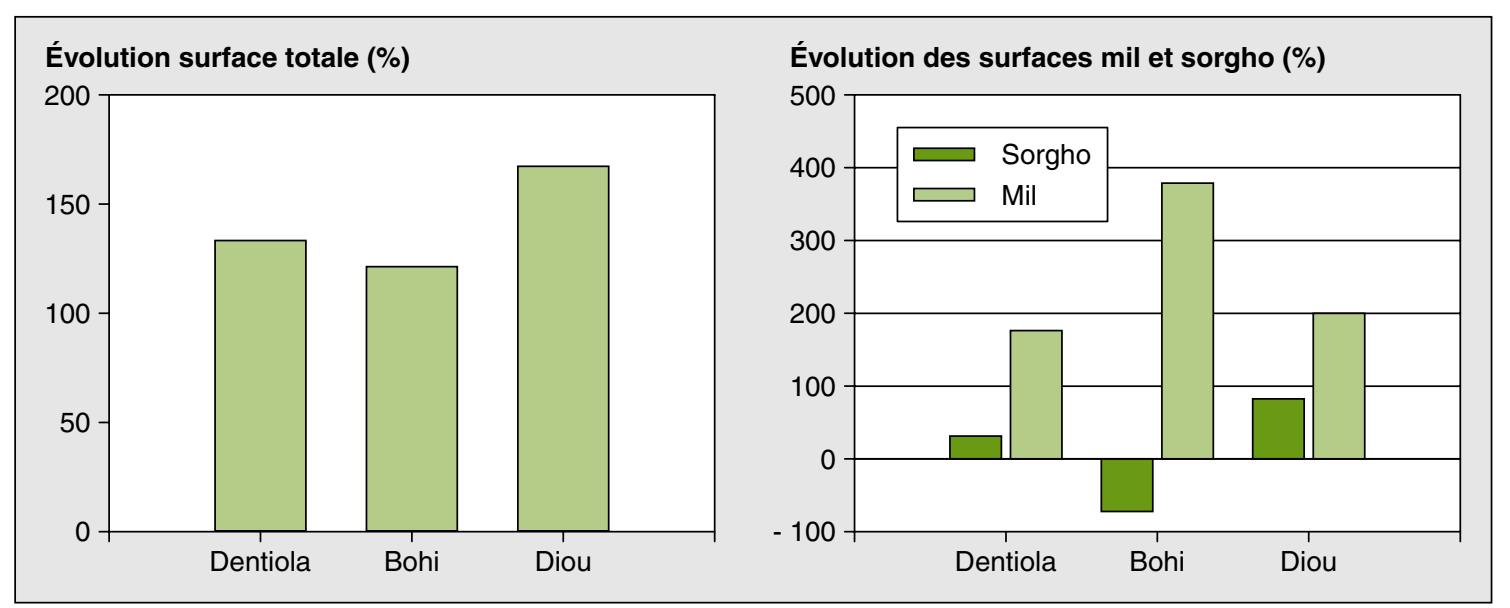

Figure 3. Augmentation en pourcentage de la surface totale et de celles consacrées au mil et au sorgho entre 1985 et 2005 sur l'échantillon de 15 exploitations dans chaque village.

Figure 3. The cultivated area increased strongly from 1985 to 2005 for the 15 farmers in each village.

\section{Diminution progressive} de la sole de sorgho

L'analyse des SC à l'échelle régionale montrait que le sorgho occupe toujours une place importante, en termes de surface cultivée/actif dans l'ensemble du bassin cotonnier, mais variable selon les régions agricoles (figure 2). Mais quand on s'intéresse à l'évolution des assolements au sein des exploitations de 1980 à 2005 , le constat est tout autre. Alors que la surface cultivée par exploitation augmente de 120 à $160 \%$ durant cette période selon les sites, les surfaces en sorgho ne s'accroissent que de $30 \%$ à Dentiola et de $80 \%$ à Diou, et diminuent de $75 \%$ à Bohi (figure 3). Le sorgho enregistre donc une baisse régulière de sa part dans les assolements : - $9 \%$ à Dentiola, - $24 \%$ à Bohi et - $6 \%$ à Diou.

\section{Mil contre sorgho}

Le coton a été le moteur de l'intensification des SC au sud du Mali. Le maïs est la première culture qui a profité de cette dynamique car il lui succède dans la rotation pour profiter de l'arrière-effet des engrais apportés sur le coton. Il en ressort que la part du maïs dans la production céréalière du Mali est passée de 12 à $28 \%$ entre 1980 et 2000 (Soumaré, 2004). Bazile et Soumaré (2004) présentent le développement du maïs comme étant la principale cause de la diminution de la sole de sorgho dans les exploitations de la région de Sikasso.

La présente étude met en exergue une nouvelle hypothèse de travail : la concurrence entre le mil et le sorgho au sein des exploitations. En effet, dans la zone d'étude, le mil progresse lui aussi au détriment du sorgho. Il s'agit là d'un résultat original qui amène le chercheur à s'interroger davantage sur les stratégies paysannes. Le mil est traditionnellement cultivé dans des conditions écologiques plus contraignantes et principalement dans la bande sahélienne (figure 2): sols moins riches, risque hydrique plus élevé et systèmes de production à faible niveau d'intrants. Dans le cas de la zone soudano-guinéenne, il se développe dans des conditions nettement plus favorables où les SC à base de coton sont plus intensifiés.

Les taux d'accroissement des surfaces en mil entre 1980 et 2005 sont très importants dans les trois sites - $180 \%$ à Dentiola, $380 \%$ à Bohi et $200 \%$ à Diou - alors que les surfaces en sorgho ne progressent que très faiblement (figure 3). Alors que la part du sorgho dans l'assolement est en baisse constante dans chaque site entre 1980 et 2005 - de 31 à $22 \%$ à Dentiola, de 27 à $3 \%$ à Bohi et de 20 à $14 \%$ à Diou - celle du mil augmente régulièrement, passant de 22 à $33 \%$ à Dentiola $(+11)$, de 12 à $23 \%(+11)$ à Bohi, et de 15 à $19 \%$ (+ 4) à Diou (figure 4).

Comment expliquer que le sorgho soit la seule culture en régression? Sa faible réponse à l'intensification par rapport au maïs est un élément d'explication. Pourtant, le mil qui est aussi considéré comme une culture peu exigeante réussit à progresser aux côtés du maïs, même si c'est dans une moindre mesure. Le mil valorise-t-il davantage que le sorgho les apports d'urée et de complexe céréale $(\mathrm{N}$,
$\mathrm{P}, \mathrm{K})$ ? On observe que les agriculteurs utilisent dans certains cas plus souvent les engrais minéraux sur le mil que sur le sorgho. La part des parcelles fertilisées en 2005 est plus élevée pour le mil que pour le sorgho tant à Bohi (35 contre $17 \%)$ et équivalente à Diou (8 contre $7 \%$ ). Cependant, à Dentiola, on note l'inverse puisque près de la moitié des parcelles en sorgho reçoivent de l'engrais contre $34 \%$ pour le mil. L'élément le plus remarquable n'est donc pas la valeur absolue de la proportion fertilisée observée aujourd'hui mais sa progression dans le temps et en parallèle à l'augmentation de la sole de mil. L'évolution du pourcentage de parcelles de mil ayant reçu de l'engrais entre 1995 et 2005 est en cela étonnante puisqu'il passe de 0 à $35 \%$ à Bohi, de 0 à $8 \%$ à Diou et de 7 à $34 \%$ à Dentiola. On peut alors supposer que la rusticité du mil se combine bien avec une assez bonne réponse aux engrais qui satisfait les objectifs des agriculteurs. En effet, en apportant quelques kilogrammes d'engrais, le paysan ne cherche pas à atteindre des rendements très élevés. Il cherche plutôt à favoriser l'implantation et le développement de la culture pour permettre l'obtention d'un rendement " moyennement " bon (Gigou, 1998).

En outre, le mil est la céréale qui se vend le mieux sur les marchés urbains maliens. Son prix a atteint 110 francs CFA le kilo contre 90 pour le sorgho et 80 pour le maïs en mars 2007. Le rendement du sorgho par rapport à celui du mil ne permet pas de combler cette différence de prix. En milieu paysan, le mil a un rendement 


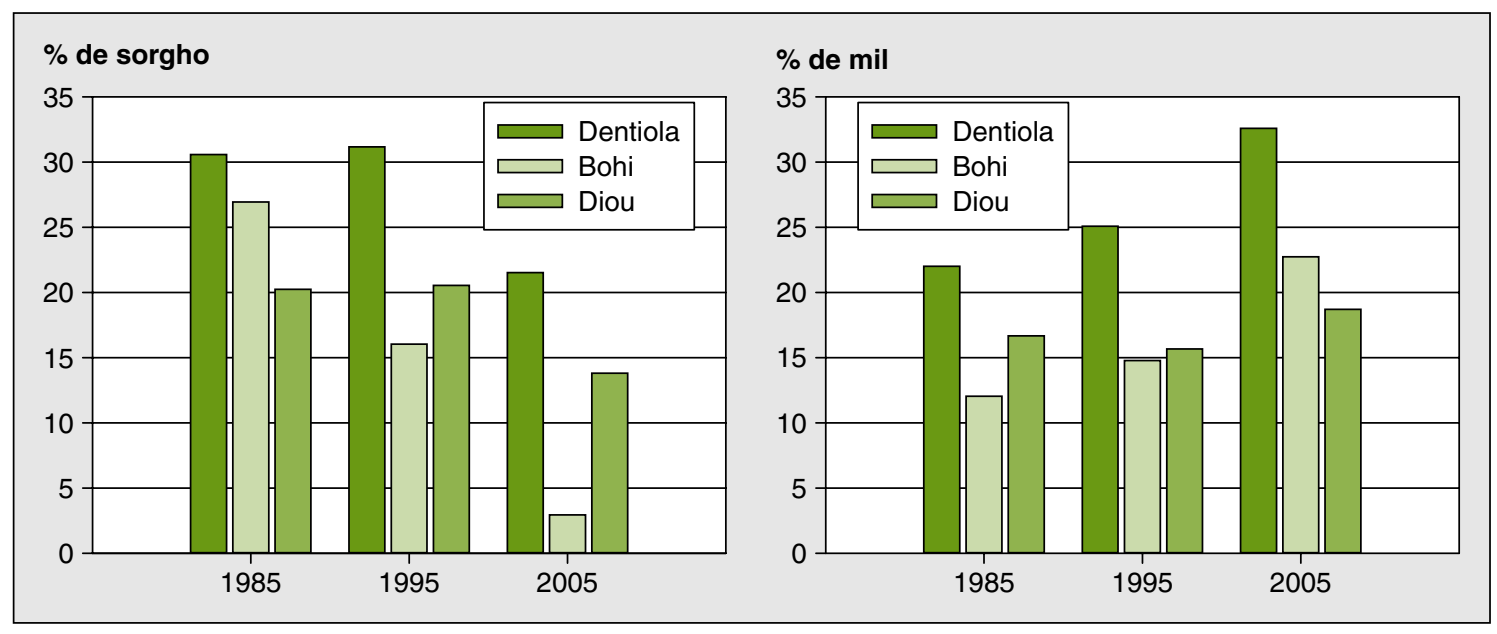

Figure 4. Évolution décroissante de la part du sorgho et du mil dans les assolements entre 1985 et 2005.

Figure 4. Sorghum role in rotation decreased in each village between 1985 and 2005.

proche de celui sorgho: $1038 \mathrm{~kg} / \mathrm{ha}$ contre $1058 \mathrm{~kg} / \mathrm{ha}$ en 2006 dans la zone CMDT. Quelques exploitants profitent maintenant de ce prix rémunérateur en basant leur stratégie de stabilisation des revenus sur le mil. Ce phénomène est particulièrement répandu à Bohi où le mil contribue significativement à la formation du revenu monétaire de 4 exploitations sur 15. Ainsi sa contribution aux revenus agricoles peut même atteindre $35 \%$ dans certaines exploitations, qui, par ailleurs, continuent toujours de cultiver le coton.

\section{Discussion \\ et conclusion}

Les paysans ont développé différents modes de mise en valeur de l'espace en le découpant en plusieurs entités distinctes (ager et saltus) mais complémentaires. Cela se traduit par une diversité d'assolement et de pratiques selon les régions agricoles du Mali-Sud.

Le sorgho occupe toujours une place importante dans les SC mais celle-ci décroît progressivement. Le mil, traditionnellement localisé dans la zone sahélienne, se développe aujourd'hui au sud du Mali. Il contribue désormais, comme le maïs, à faire reculer le sorgho. De plus, il reçoit de plus en plus de fertilisants minéraux. Cette progression au détriment du sorgho est d'autant plus surprenante que du point de vue agronomique le sorgho a un potentiel de rendement plus élevé que le mil. À Bohi, où la progression du mil est plus importante, certains paysans estiment que le sorgho "n'accepte plus leur sol". Le mil, plus rustique, le remplace très certainement dans les sols les plus pauvres (Bazile et al., 2004).

Ces constats invitent le chercheur à explorer davantage les stratégies et les pratiques des paysans. La régression en surface du sorgho a lieu en même temps que l'érosion variétale de cette culture, constatée dans cette région au sud du Mali (Kouressy et al., 2003). En effet, entre 1978 et 1999, $60 \%$ des variétés de sorgho au sud du Mali ont été perdues contre $25 \%$ au nord. Cependant, on peut se demander lequel des deux phénomènes est la conséquence ou cause de l'autre. Dans le même ordre d'idée, on peut s'interroger sur le lien entre l'accroissement des soles de mil et le nombre de variétés cultivées.

Le mil se développe donc et devient progressivement une culture commerciale dans une conjoncture où les paysans peuvent de moins en moins compter sur les revenus du coton suite aux difficultés actuelles de la filière. Le revenu qu'il procure participe de ce fait à la sécurisation monétaire des exploitations et à leur viabilité économique ponctuelle.

Les céréales traditionnelles - mil et sorgho - ont encore un rôle important à jouer au sein des SP à cause de la forte variabilité du climat et de la saturation progressive de l'espace conduisant à la mise en culture de sols à plus forte contrainte agri- cole (Bazile et al., 2008). Le maintien des variétés locales de ces céréales contribuera à la durabilité et à la résilience des systèmes agraires. Ces variétés ont une forte capacité d'adaptation aux contraintes écologiques. C'est le cas des variétés photopériodiques qui permettent de faire face à la variabilité climatique ou encore les types Séguetana, résistants au striga, qui tolèrent l'acidité des sols.

Les tendances observées sont issues d'enquêtes sur un petit échantillon de 15 exploitations dans trois villages ; elles méritent d'être étendues et comparées aux situations d'autres villages et d'autres régions agricoles du Mali-Sud.

\section{Références}

Bazile D, Dembélé S, Soumaré M, Dembélé $D$. Utilisation de la diversité variétale du sorgho pourvaloriser la diversité des sols au Mali. Cah Agric 2008; 17 : 86-94.

Bazile D, Soumaré M. Pratiques paysannes de gestion de la diversité variétale en réponse à la diversité écosystémique. Le cas du sorgho [Sorghum bicolor (L) Moench] au Mali. Cah [Sorghum bicolor (L)
Agric $2004 ; 13: 480-7$.

Bazile D, Soumaré M, Dembélé J. Conserver l'agrobiodiversité pour la stabilité de la production agricole. Atelier sous-régional sur la biodiversité agricole en Afrique de l'Ouest, 15 biodiversité agricole en Afrique de l'Ouest, 15
au 19 décembre. GTZ/FAO, Bamako, Mali, 2004.

Dufumier M. Étude des systèmes agraires et typologie des systèmes de production agricole dans la région cotonnière du Mali. Paris : Institut national agronomique de Paris-Grignon (Ina-PG), 2005 
Gigou J. Les céréales dans les systèmes de culture des régions semi-arides d'Afrique de I'Ouest. In : Reyniers F-N, Bacci L, eds. Le futur des céréales photopériodiques en Afrique. Montpellier : Centre de coopération internationale en recherche agronomique pour le développement (Cirad); Cycle d'enseignement supérieur en industries agroalimentaires (CeSIA), 1998

Jouve P. Système de culture et organisation spatiale des territoires. Comparaison entre agriculture tempérée et agriculture tropicale. In : Dugué $\mathrm{P}$, Jouve $\mathrm{P}$, eds. Organisation spatiale et gestion des ressources et des territoires ruraux Actes du colloque international, Montpellie 25-27 février 2003. Montpellier: Centre de coopération internationale en recherche agronomique pour le développement (Cirad), unité mixte de recherche Sagert; Cnearc ; Engref, 2003

Kouressy M, et al. La dynamique des agrosystèmes un facteur explicatif de l'érosion variétale du sorgho: le cas de la zone Mali-Sud. In Dugué $\mathrm{P}$, Jouve $\mathrm{P}$, eds. Organisation spatiale et gestion des ressources et des territoires ruraux. Actes du colloque international, Montpellier 25-27 février 2003. Montpellier: Centre de coopération internationale en recherche agronomique pour le développement (Cirad), unité mixte de recherche Sagert; Cnearc Engref, 2003.

Milleville P, Serpantier G. Dynamiques agrai res et problématique de l'intensification en Afrique soudano-sahélienne. In : Milleville $\mathrm{P}$, ed. Une agronomie à l'œuvre Pratiques pay sannes dans les campagnes du Sud. Paris Quae éditions ; Arguments, 2007 : 130-40.
Soumaré M, Bazile D, Diakité CH. Zonage agroécologique, Projet Caractérisation des dynamiques agraires en zones cotonnières du Mali, Rapport Final IER-CP, 2006

Soumaré M. Prévision de l'aire de diffusion de variétés de sorgho au Mali, couplage entre modèle de croissance des cultures et système d'information géographique. Mémoire de DEA, Géographie et Pratique du développement, université Paris X Nanterre, 2004.

Tersiguel P. Le pari du tracteur. La modernisation de l'agriculture cotonnière au Burkina Faso. Paris : Orstom éditions, 1995.

Wood D, Lenné J-M. Agrobiodiversity and Natural Diversity: Some Parallels. In : Wood D, Lenné J-M, eds. Agrobiodiversity: characterization, utilization and management. New York : CABI Publishing, 1999. 